\title{
The efficacy of chemotherapy in the patients with stage II colon cancer associated with number of high-risk factors
}

\author{
Min Joo Kim', Seung-hyun Baek', Sanghwa Ko ${ }^{2}$ \\ 'Department of Surgery, Biomedical Research Institute, Pusan National University Hospital, Busan; \\ ${ }^{2}$ Department of Surgery, Busan Medical Center, Busan, Korea
}

Purpose: This study assessed the effect of chemotherapy over stage II colon cancer in terms of presence of high-risk factors.

Methods: Data were retrospectively reviewed for 364 patients with stage II colon cancer who underwent curative surgery between January 2007 and December 2012. High-risk factors of stage II colon cancer were examined, and the overall survival (OS) rates were analyzed. Survival benefit of adjuvant chemotherapy was also analyzed.

Results: One hundred and fifteen cases had exclusively single high-risk factor and 194 cases were negative for high-risk factors. Postoperative chemotherapy was performed in 262 of 364 patients (72.0\%). The 5-year OS was 79.4\% and 86.6\% for patients without adjuvant chemotherapy and those with chemotherapy, respectively. The 5 -year OS was $88.2 \%$ and $83.3 \%$ for patients having exclusively single high-risk factor with adjuvant chemotherapy and those without chemotherapy, respectively.

Conclusion: Adjuvant chemotherapy for patients with stage II colon cancer having exclusively single high-risk factor could be omitted, weighing up the survival benefit and side effect of chemotherapy.

Keywords: Colorectal neoplasms, Drug therapy, Survival analysis

\section{INTRODUCTION}

Treatment of colon cancer consists of surgical resection and chemotherapy. Stage II colon cancer is categorized into a high-risk group and low-risk group for recurrence, and chemotherapy is recommended for the high-risk group [1]. High-risk factors are perineural invasion, lymphovascular emboli, lymph node harvest less than 12, T4 stage, positive resection margin, obstruction, and perforation [2-4].

Received: Oct 25, 2017 Revised: Dec 10, 2018 Accepted: Dec 18, 2018 Correspondence to: Sanghwa Ko

Department of Surgery, Busan Medical Center, 359 World cup-daero,

Yeonje-gu, Busan 47527, Korea

Tel: +82-51-607-2851, Fax: +82-51-507-3001

E-mail: kohssang@gmail.com

ORCID: Min Joo Kim (https://orcid.org/0000-0003-4118-2958), Seung-hyun Baek (https://orcid.org/0000-0003-0175-2047), Sanghwa Ko (https://orcid.org/00000001-5677-2649)

Copyright (C) 2018 Korean Society of Surgical Oncology

This is an Open Access article distributed under the terms of the Creative Commons Attribution Non-Commercial License (http://creativecommons.org/licenses/by-nc/4.0) which permits unrestricted non-commercial use, distribution, and reproduction in any medium, provided the original work is properly cited.
There is no doubt over treatment with chemotherapy for stage II colon cancer patients having high-risk factors. However, chemotherapy could cause side effects that makes patients' compliance lower. Physicians face this dilemma, especially with patients who are old or have severe comorbidities. Therefore, this study was designed to determine the effectiveness of chemotherapy for patients with stage II colon cancer according to the number of high-risk factors.

\section{METHODS}

From January 2007 to December 2012, 364 patients with stage II colon cancer who underwent curative resection were enrolled. Poor differentiation, lymphovascular emboli, perineural invasion, less than 12 harvested lymph nodes, T4 stage, malignancy-positive surgical margin, and cancer obstruction or perforation are considered high-risk factors. After surgery, postoperative 5-fluorouracil (5-FU)-based chemotherapy is administered orally.

Patients with stage II colon cancer were categorized into two groups depending on the performance of adjuvant chemotherapy and according to the numbers of positive high-risk factors. Age, 
sex, and tumor location were also compared as variables. Postoperative 5-year survival rates were investigated. Disease-free survival was not analyzed due to the small population of subgroups.

All of the patients underwent follow-up observation every 3 to 6 months for 2 years, and then every 6 months for 3 years. Follow-up examinations included a clinical history, physical examination, serum carcinoembryonic antigen assay, chest $\mathrm{X}$-ray, abdominopelvic computed tomography or magnetic resonance imaging, colonoscopy, and positron emission tomography scanning if available.

Statistical analysis was performed by MedCalc (Ostend, Belgium). Analysis of differences between the two groups was by t-test or Fisher exact test. Analysis of overall survival (OS) and disease-free survival was performed by the Kaplan-Meier method and log-rank test. A P-value $<0.05$ was set to indicate statistical significance. This study was approved by the Institutinal Review Board of Pusan National University Hospital (IRB No. H-17080003-057) and performed in accordance with the principles of the Declaration of Helsinki. The written informed consent was obtained.

\section{RESULTS}

Clinicopathological characteristics of patients with stage II colon cancer in this study was shown in Table 1. In terms of high-risk factors, 194 patients had none of the risk factors. Exclusively single high-risk factors, meaning patients having any kind of single high-

Table 1. Characteristics of patients with stage II colon cancer

\begin{tabular}{lc}
\hline Characteristic & Total patients $(n=364)$ \\
\hline Age (yr) & $64.9 \pm 11.7$ \\
Sex & $227(62.4)$ \\
Male & $137(37.6)$ \\
Female & \\
Location & $117(32.2)$ \\
Ascending colon & $30(8.2)$ \\
Transverse colon & $42(11.5)$ \\
Descending colon & $175(48.1)$ \\
Sigmoid colon & \\
Positive for high-risk factors & $79(21.7)$ \\
Perineural invasion & $61(16.8)$ \\
Lymphovascular emboli & $33(9.1)$ \\
Harvested lymph nodes <12 & $16(4.4)$ \\
Poorly differentiated & $25(6.9)$ \\
T4 & $24(6.6)$ \\
Obstruction, perforation & $3(0.8)$ \\
Margin involvement & $194(53.3)$ \\
Negative for high-risk factors & $115(31.6)$ \\
\hline Exclusively single high-risk factor &
\end{tabular}

Values are presented as mean \pm standard deviation or number $(\%)$. risk factor were observed in 115 patients. One patient had four of high-risk factor. Adjuvant chemotherapy was given to 262 patients regardless of high-risk factors. Forty-five patients underwent no chemotherapy even with more than one high-risk factor (Table 2).

The 5-year OS rate of all patients was $84.6 \%$, respectively. According to the presence of chemotherapy, 5-year OS was $86.6 \%$ and $79.4 \%$ for patients with chemotherapy and without chemotherapy. The 5-year OS rate according to number of high-risk factors in this study was summarized in Table 3. Comparing two groups of no high-risk factor and exclusively single high-risk factor, the 5 -year OS rate was $87.1 \%$ and $87.0 \%$, respectively. The 5 -year OS rate was $85.1 \%$ and $87.8 \%$ in patients having none or exclusively single high-risk factors who underwent adjuvant chemotherapy and no chemotherapy, respectively $(\mathrm{P}=0.505)$.

In the univariate analysis for OS, T4 stage and over 65 years old were significantly influenced having a worse $\mathrm{OS}$ rate $(\mathrm{P}=0.003$ and $\mathrm{P}=0.015$ ). Including two more factors as adjuvant chemotherapy and number of high-risk factors, multivariate analysis showed that single factors of over 65 years old was significantly associated with a worse OS rate.

\section{DISCUSSION}

Although the incidence of colon cancer is gradually decreasing, it

Table 2. Number of patients according to numbers of high-risk factors and presence of adjuvant chemotherapy

\begin{tabular}{lccc}
$\begin{array}{l}\text { No. of high-risk } \\
\text { factors }\end{array}$ & $\begin{array}{c}\text { No. of patients } \\
(n=364)\end{array}$ & $\begin{array}{c}\text { Without adjuvant } \\
\text { chemotherapy } \\
(n=102)\end{array}$ & $\begin{array}{c}\text { With adjuvant } \\
\text { chemotherapy } \\
(n=262)\end{array}$ \\
\hline 0 & 194 & 57 & 137 \\
1 & 115 & 30 & 85 \\
2 & 41 & 10 & 31 \\
3 & 13 & 5 & 8 \\
4 & 1 & 0 & 1 \\
\hline
\end{tabular}

Values are presented as number.

Table 3. The 5-year OS rate according to high-risk factors

\begin{tabular}{lcccc}
\hline $\begin{array}{l}\text { No. of high-risk } \\
\text { factors }\end{array}$ & $\begin{array}{c}\text { 5-Year } \\
\text { OS rate }\end{array}$ & $\begin{array}{c}\text { Without adjuvant } \\
\text { chemotherapy }\end{array}$ & $\begin{array}{c}\text { With adjuvant } \\
\text { chemotherapy }\end{array}$ & P-value \\
\hline Overall & 84.6 & 79.4 & 86.6 & 0.082 \\
0 & 87.1 & 86.0 & 87.6 & 0.538 \\
1 & 87.0 & 83.3 & 88.2 & 0.769 \\
2 & 70.7 & 50.0 & 77.4 & 0.087 \\
3 & 69.2 & 40.0 & 87.5 & 0.066 \\
4 & 100 & - & 100 & - \\
\hline
\end{tabular}

Values are presented as percentage.

OS, overall survival. 
is still the second most common cancer. The standard treatment for colon cancer involves a combination of surgical resection, chemotherapy, and sometimes radiotherapy, and the need for treatment is almost always obvious except for stage IV colon cancer, which requires palliative care [1]. The recommended treatment for stage II colon cancer is ether follow-up observation or chemotherapy depending on the presence of risk factors and the pathology report [5-7]. For these patients, a 5-FU based oral anticancer drug is generally prescribed. Oral anticancer drugs have fewer side effects than oxaliplatin-based intravenous anticancer drugs, but severe side effects such as hand-foot syndrome sometimes occur. Therefore, it is hard to make a proper decision to prescribe anticancer drugs for stage II colon cancer patients who have underlying disease or are of old age.

Oncologic outcome of stage II colon cancer is reported as 70\% to $85 \%$ in 5 -year OS rate $[8,9]$. The effect of adjuvant chemotherapy has been well documented in patients with high-risk factors. Casadaban et al. [9] showed the improvement of OS in 15\% to $20 \%$. However, different aspects of effect over adjuvant chemotherapy in stage II colon cancer was reported in studies. Verhoeff et al. [10] concluded that only pT4 factor could influence OS rate with chemotherapy, and Babcock et al. [11] also reported similar result. In our study, pT4 factor showed a strong but insignificant influence on survival outcome. Over 65 years of age only affected OS rate significantly in multivariate analysis.

Patients with stage II colorectal cancer are often recommended to undergo adjuvant chemotherapy if they have just one high-risk factor, including perineural invasion, after surgery. Nevertheless, side effects such as hand-foot syndrome, diarrhea, and mucositis following oral chemotherapy can occur and chemotherapy is terminated early in up to $50 \%$ of cases [12]. The proportion of patients treated with oral chemotherapy who reported that the treatment was "very convenient" or that they were "very satisfied" was $60 \%$ to $70 \%$ [13]. Early termination of chemotherapy was reported in $13.8 \%$, and $55.2 \%$ of patients experienced dose reduction $[14,15]$. In our study, early termination of chemotherapy was reported in 42 patients (11.5\%) with unreported cause and dose reduction not assessed.

The present study has the inherent limitations of a retrospective study and small sample size of relevant patients. Therefore further investigation is required to reach a concrete conclusion. The criteria of old age could differ between study groups (e.g., over 70 years old). However, this study highlights the lack of a significant survival benefit of adjuvant chemotherapy in patients having none or exclusively single high-risk factors of stage II colon cancer. It will be necessary to evaluate a larger sample size to draw a firm conclusion.

\section{CONFLICT OF INTEREST}

No potential conflict of interest relevant to this article was reported.

\section{REFERENCES}

1. Benson AB 3rd, Bekaii-Saab T, Chan E, Chen YJ, Choti MA, Cooper HS, et al. Localized colon cancer, version 3.2013: featured updates to the NCCN guidelines. J Natl Compr Canc Netw 2013;11: 519-28.

2. Marshall JL, Haller DG, de Gramont A, Hochster HS, Lenz HJ, Ajani JA, et al. Adjuvant therapy for stage II and III colon cancer: consensus report of the International Society of Gastrointestinal Oncology. Gastrointest Cancer Res 2007;1:146-54.

3. Burdy G, Panis Y, Alves A, Nemeth J, Lavergne-Slove A, Valleur P. Identifying patients with T3-T4 node-negative colon cancer at high risk of recurrence. Dis Colon Rectum 2001;44:1682-8.

4. Fujita S, Nakanisi Y, Taniguchi H, Yamamoto S, Akasu T, Moriya Y, et al. Cancer invasion to Auerbach's plexus is an important prognostic factor in patients with pT3-pT4 colorectal cancer. Dis Colon Rectum 2007;50:1860-6.

5. Suzuki T, Suwa K, Ogawa M, Eto K, Kawahara H, Fujita T, et al. Adjuvant chemotherapy for the perineural invasion of colorectal cancer. J Surg Res 2015;199:84-9.

6. Knijn N, Mogk SC, Teerenstra S, Simmer F, Nagtegaal ID. Perineural invasion is a strong prognostic factor in colorectal cancer: a systematic review. Am J Surg Pathol 2016;40:103-12.

7. Huh JW, Lee JH, Kim HR, Kim YJ. Prognostic significance of lymphovascular or perineural invasion in patients with locally advanced colorectal cancer. Am J Surg 2013;206:758-63.

8. O'Connor ES, Greenblatt DY, LoConte NK, Gangnon RE, Liou JI, Heise CP, et al. Adjuvant chemotherapy for stage II colon cancer with poor prognostic features. J Clin Oncol 2011;29:3381-8.

9. Casadaban L, Rauscher G, Aklilu M, Villenes D, Freels S, Maker AV. Adjuvant chemotherapy is associated with improved survival in patients with stage II colon cancer. Cancer 2016;122:3277-87.

10. Verhoeff SR, van Erning FN, Lemmens VE, de Wilt JH, Pruijt JF. Adjuvant chemotherapy is not associated with improved survival for all high-risk factors in stage II colon cancer. Int J Cancer 2016; 139:187-93.

11. Babcock BD, Aljehani MA, Jabo B, Choi AH, Morgan JW, Selleck MJ, et al. High-risk stage II colon cancer: not all risks are created equal. Ann Surg Oncol 2018;25:1980-5.

12. Brearley SG, Craven O, Saunders M, Swindell R, Molassiotis A. Clinical features of oral chemotherapy: results of a longitudinal prospective study of breast and colorectal cancer patients receiving capecitabine in the UK. Eur J Cancer Care (Engl) 2010;19:425-33. 
13. Kopec JA, Yothers G, Ganz PA, Land SR, Cecchini RS, Wieand HS, et al. Quality of life in operable colon cancer patients receiving oral compared with intravenous chemotherapy: results from National Surgical Adjuvant Breast and Bowel Project Trial C-06. J Clin Oncol 2007;25:424-30.

14. Law CC, Fu YT, Chau KK, Choy TS, So PF, Wong KH. Toxicity profile and efficacy of oral capecitabine as adjuvant chemotherapy for Chinese patients with stage III colon cancer. Dis Colon Rectum 2007;50:2180-7.

15. Pfeiffer P, Mortensen JP, Bjerregaard B, Eckhoff L, Schonnemann K, Sandberg E, et al. Patient preference for oral or intravenous chemotherapy: a randomised cross-over trial comparing capecitabine and Nordic fluorouracil/leucovorin in patients with colorectal cancer. Eur J Cancer 2006;42:2738-43. 